Preparing IAS Officer Trainees for the Role of District Magistrate: A Competency-based Approach

\author{
Sanjeev Chopra \\ Ram Kumar Kakani \\ Vishal Gupta
}

W.P. No.2014-07-02

July 2014

The main objective of the working paper series of the IIMA is to help faculty members, research staff and doctoral students to speedily share their research findings with professional colleagues and test their research findings at the pre-publication stage. IIMA is committed to maintain academic freedom. The opinion(s), view(s) and conclusion(s) expressed in the working paper are those of the authors and not that of IIMA.

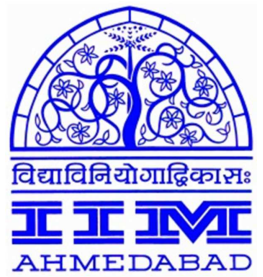

INDIAN INSTITUTE OF MANAGEMENT

AHMEDABAD-380 015

INDIA 


\title{
PREPARING IAS OFFICER TRAINEES FOR THE ROLE OF DISTRICT MAGISTRATE: A COMPETENCY-BASED APPROACH
}

\section{SANJEEV CHOPRA}

Joint Director, Lal Bahadur Shastri National Academy of Administration

Mussoorie - 248179

e-mail: s.chopra@ias.nic.in

\section{RAM KUMAR KAKANI}

Director, National Centre for Leadership Development and Competency Assessment Lal Bahadur Shastri National Academy of Administration

Mussoorie - 248179

e-mail:rk.kakni@nic.in

\author{
VISHAL GUPTA \\ Assistant Professor, Organizational Behavior Group \\ Indian Institute of Management Ahmedabad \\ Vastrapur, Ahmedabad - 380015 \\ e-mail:vishal@iimahd.ernet.in
}

\begin{abstract}
The Indian Administrative Service (IAS) officers occupy a strategic position in Indian public governance system. Government has generally laid a lot of emphasis on the training programmes for IAS officers to ensure that they are equipped with the right set of knowledge, skills and attitude to effectively perform in the varied assignments that they occupy. It is increasingly being recognized that more than knowledge, skill and attitude, proficiency in certain deep seated abilities result in superior and more effective performance of an individual in an organizational setting. These deep seated abilities are commonly termed as competencies. In this paper an exercise has been undertaken to identify the key competencies which are required for effectively performing the role of a District Magistrate (DM). The focus of the two years training programme at Lal Bahadur Shastri National Academy of Administration, (LBSNAA) is to equip the officers for the first decade of service during which they are also expected to serve as District Magistrates (DM). It is expected that clarity about the competencies required to become an effective DM will facilitate more efficient human resource management of the cadre of IAS officers including training, placement and performance management. This research paper based on extensive survey methodology is an attempt in that direction.
\end{abstract}

Keywords: Indian Administrative Service (IAS); Civil Service; Competency; Leadership; District Magistrates (DM) 


\section{Acknowledgements}

Authors thank all the officers (District Magistrates) who participated in the study and gave their valuable inputs, time and support. The authors gratefully acknowledge the support of Ms. Meena Surie of Wilson of M/s Center for Creative Leadership and Dr. Ashutosh P. Singh of National Center for Good Governance for helping them in conducting this study and in preparing different parts of the manuscript. 


\section{PREPARING IAS OFFICER TRAINEES FOR THE ROLE OF DISTRICT MAGISTRATE: A COMPETENCY-BASED APPROACH}

\section{Introduction}

From a post-colonial civil service, Indian Administrative Service (IAS) has evolved into a premier civil service, with IAS officers occupying top administrative positions in both the Union Government and State Governments. Recruitment to the IAS is through an annual competitive examination conducted by the Union Public Service Commission, Government of India (GoI). The raison d'etre of the IAS has been described by Sardar Patel, India's first Home Minister. While addressing the Constituent Assembly in 1949, he asserted “...you will not have a united India, if you have do not have a good all-India service which has the independence to speak out its mind, which has the sense of security ... this Constitution is meant to be worked by a ring of service which will keep the country intact."

The training of India's higher civil services has historically been accorded high priority by the central government. There are three All-India Services (AIS) - while the IAS and the Indian Police Service (IPS) were constituted around independence, the Indian Forest Service (IFS) was constituted later in 1966. AIS Officers are recruited by the Union, placed at the disposal of the state governments, and work at both the state and federal level (Aggrawal, 2014).

The two-year induction training of IAS officers has evolved over time keeping pace with the changes in polity, society and economy. The induction training is designed to equip officer trainees to shoulder the responsibilities assigned in the first 8-10 years of service during which period they also function as a District Magistrate (DM). The content has been periodically revamped based on the recommendations of Syllabus Review Committees. In recent years, competency-based Human Resource Management (HRM) in civil services has engaged the attention of policy makers around the world. In this context, we examine the 
competencies that are required to become an effective DM and how they might impact on the induction training of IAS officers. In this paper, we attempt to answer the above question using a survey methodology. We draw possible inferences and implications on the future induction training programme. In Section 2, we describe the framework of our study along with giving a brief contemporary background. Section 3 presents the research methodology and section 4 presents the important findings along with the suggestions for induction training module. Section 5 concludes the study by listing our suggestions for future research work and the limitations of this study.

\section{Contemporary Background and Framework of Study}

\subsection{Induction Training for IAS Officers}

Upon entry, officer trainees participate in induction training for a period of two years under the aegis of the Lal Bahadur Shastri National Academy of Administration (LBSNAA, hereafter Academy) ${ }^{1}$ at Mussoorie. While, IAS has a conspicuous "generalist" orientation, many of its incoming officers have strong domain specializations -- such as in engineering, law, medicine, business studies and so forth. The profile of recent batches is given at Annexure-1. The batch profile has been divided in two periods: first relates to 2000-2008 and other pertains to 2009-2013. An effort has been made to ascertain whether the worldwide financial crisis of 2008 has impacted the profile of the IAS batches. It emerges from the comparison that the percentage officer trainees with professional qualifications (includes B. Tech., BDS, B.E., B.Sc., CA, LLB/LLM, MBA, MBBS, MD) has increased from $50 \%$ to 63\%. The increase in percentage of engineers going up from one-fifth of the batch to over one-third of the batch is significant.

\footnotetext{
${ }^{1}$ LBSNAA was set up at Mussoorie in 1959 by the merger of the IAS Training School at Delhi and the IAS Staff College at Shimla.
} 
In the current system, the entry-level two year (103 weeks) training is also a probationary period and includes the following components:
a. Foundation Course - 15 weeks
b. IAS Professional Course (Phase I) - 26 weeks
c. District Training -54 weeks
d. IAS Professional Course (Phase II) - 8 weeks

The essential elements of the various components of induction training, designed to equip the officers for the first 8-10 years of service are given below:

* The Foundation Course is a distinctive programme during which different higher civil services including the three All-India civil services train together for fifteen weeks before embarking on their service-specific professional training. Besides imparting an understanding of the "machinery of the government" and of the political, social, economic and administrative environment, the Foundation Course also aims to build esprit de corps in order to foster greater coordination among different civil services;

* The specific purpose of the Phase I and Phase II components of the induction training is to equip officers with the knowledge, skills and attitudes required to handle field assignments, particularly the role of DM;

* The Phase I and Phase II professional programmes are interspersed with 54 week district training which exposes the officer trainees to the ground situation. It provides them an opportunity to closely study the system of district administration and gain hands-on experience through independent charge of subordinate offices such as Block and Tehsil;

* The two-year induction training is based on the following assumptions and commitments: 
o "learning by doing" is extremely effective and so Officer Trainees must be mandated to shoulder independent responsibilities in junior or subordinate positions during their District Training;

o theoretical inputs should be blended with exposure to field realities and the training must follow the "sandwich" pattern; i.e. institutional training must be interspersed by field training;

- developing strong esprit de corps among officers will improve professional interactions within the community;

O a strong system of mentorship must exist both at the Academy and in the district; and

○ a strong ethical foundation must be built to successfully tackle the challenges of service life (Aggrawal, 2014).

* The district assignments of an IAS officer typically culminate in his/her being assigned the responsibility of a DM after 3-7 years of service ${ }^{2}$. Subsequently to the induction training, there is a structured in-service training programme which takes place after every 8 to 10 years of service ${ }^{3}$.

\subsection{Recent Review and Recommendations for IAS Induction Training Programme}

A Syllabus Review Committee constituted by Department of Personnel and Training (DoPT), GoI regularly updates the contents of induction training in consultation with stakeholders including the Directors of other Central Training Institutes and Administrative Training Institutes at State level. More recently, broad and in-depth reviews have been taken up by the Ayyar (2007) and Aggrawal (2014) committees.

\footnotetext{
${ }^{2}$ The number of years taken to become a DM varies across states and may take anywhere between 3 to 7 years.

3 The mid-career training programme for IAS officers was introduced in 2007 with the aim of imparting structured in-service training to IAS officers to prepare them for higher levels of responsibilities. Hence, Phase III, IV and V are organized for officers with 8-10 years, 16-18 years and 26-28 years of seniority respectively.
} 
The Aggrawal Committee report builds on the review and recommendations of the earlier Ayyar Committee. The mandate of the Kiran Aggrawal Committee was to consider the current induction training from several perspectives. The first is the changing demographics of IAS entrants, such as age, educational qualifications, and prior work experiences. The second angle is the rapid infusion of information in the public domain made possible by technology. The third is the volatile socio-economic and political changes happening in the country and its impact on the work environment. The Committee was mandated with analyzing the implications of these and other changes for updating programme design and delivery and the duration of induction training.

The Committee's review of issues and recommendations are comprehensive. At the broad level, there are three aspects of a "philosophy of development" that are addressed:

Leadership Development Architecture, which outlines seven guiding principles for the induction training ${ }^{4}$, which is undertaken within the context of the Civil Services Code of Conduct and National Service Values. It is proposed that the Induction Training be seen as a "watershed training event."

* Competency Development, which describes how the 2nd Administrative Reforms Commission and the National Training Policy (2012) have recommended the adoption of a competency-based approach to HRM, including capacity building. A competency-based HRM system can potentially transform the civil service by ensuring that the cadre of IAS officers is competent at meeting the requirements of a variety of roles.

Participant-centered Continuous Learning, which means engaging Officer Trainees as active participants in the learning process, encouraging them to treat every new

\footnotetext{
${ }^{4}$ For details, kindly refer to Annexure-2.
} 
position and challenge as a learning opportunity, and utilizing adult learning principles in the design and delivery of training.

Broadly, the Committee has presented five-pronged recommendations. Firstly, it has argued for revisiting the philosophy that anchors induction training and making it more competency-based. Secondly, it has made out a case for reducing the duration from the present two years to around one-and-a-half years. Thirdly, it has suggested some incremental changes in the syllabus prescribed by the Ayyar Committee, keeping in view the new UPSC General Studies syllabus and also to better address the felt needs of the trainees. The fourth set of recommendations pertain to pedagogical methods being currently employed in the Academy and bringing them up-to-date with those followed in leading higher education institutions to foster greater 'adult' and "participant-centered" learning . This can be facilitated by harnessing the benefits of information technology. Lastly, certain systemic changes have also been proposed for the consideration of the Ministry that may facilitate better conduct of training at the Academy.

\subsection{Research Focus}

In the preceding sub-sections an overview of IAS, its induction training programme, and the processes by which programmes for training and developing officers are continually reviewed and revised has been provided. This has been done in order to provide the backdrop to recommend a competency-based approach to prepare IAS Officer Trainees for their future roles. The objective of this paper is to address one critical question: What competencies are essential for IAS Officers to be effective as DMs?

To achieve this objective, we begin by describing the Competency Dictionary ${ }^{5}$ - this provides a framework for competency development that has been adopted by the GoI for

\footnotetext{
${ }^{5}$ GoI-UNDP Project 'Strengthening Human Resource Management of Civil Service'. Competency-based Human Resource Management for the Indian Civil Service, http://persmin.gov.in/otraining/Competency\%20Dictionary\%20for\%20the\%20Civil\%20Services.pdf, (accessed 3.06.2014).
} 
training its civil service officers. This is followed by a description of the process by which a subset of eight competencies, and proficiency levels for each of those eight competencies, has been identified for the role of DM. We will also discuss the implications of applying a competency-based approach to the design and delivery of induction training programme at Academy.

\subsection{Development of a Competency Dictionary for the Indian Civil Service}

In the last few decades of extensive empirical work in the domain of organizational behavior, it has emerged that more than mere domain knowledge, proficiencies in certain deep seated abilities and skills results in superior and more effective performance of an individual in an organizational setting. These deep seated abilities are commonly termed as 'competencies'. In modern world, often, they represent the baseline requirements for a job. Competencies are fundamental characteristics of an employee such as knowledge, skills, traits, motives, attitudes, values and other personal characteristics. Knowledge and skills are observable and are typically baseline requirements for a job. Thus knowledge and skills are "threshold competencies" that are commonly used to match people to jobs. Traits, motives, attitudes, and values are more difficult to observe and are "differentiating competencies" which are more personal characteristics that are significant drivers of superior performance. Work on competencies has moved at a fast pace and lately the focus has shifted to terminologies such as meta-competency i.e., ability to connect competencies in a synergy.

The Department of Personnel and Training of the GoI initiated the project named "Strengthening HRM of Civil Service" in the year 2011 in collaboration with the United Nations Development Programme (UNDP). The project was undertaken to support the GoI to shift towards Competency-based HRM for the Indian Civil Services and build an enabling environment for developing civil servants so they can perform in a more effective manner. A 
primary outcome of this initiative was the creation of a Competency Dictionary and an Implementation Toolkit (DoPT, 2013) ${ }^{6}$. A Competency Dictionary is a collection of competencies that have been identified for an organisation or set of organisations. The Competency Dictionary for Civil Services has been developed in consultation with a large number of civil servants in the Centre and State governments. These included Secretaries to the GoI, Cadre Controlling Authorities, Chief Secretaries of the States and winners of Prime Minister's awards. The overarching purpose for developing a Civil Services Competency Dictionary is to foster more effective, efficient, and transparent and accountable public administration at the national and state levels. Toward this end, the Civil Services Competency Dictionary identifies 25 generic or core competencies across the various roles and positions of civil service employees.

The 25 core competencies have been grouped in four sets: Ethos, Ethics, Equity and Efficiency, which are regarded as fundamental features of the Indian Civil Service and the pillars of good governance and citizen centric administration. The Competency Dictionary framework for the Indian Civil Service is depicted in Figure 1 below.

\footnotetext{
${ }^{6}$ Refer the DoPT website URL http://persmin.gov.in/otraining/CompetencyDictionary.asp for the both of these documents.
} 
Figure 1: Competency Framework for Indian Civil Service

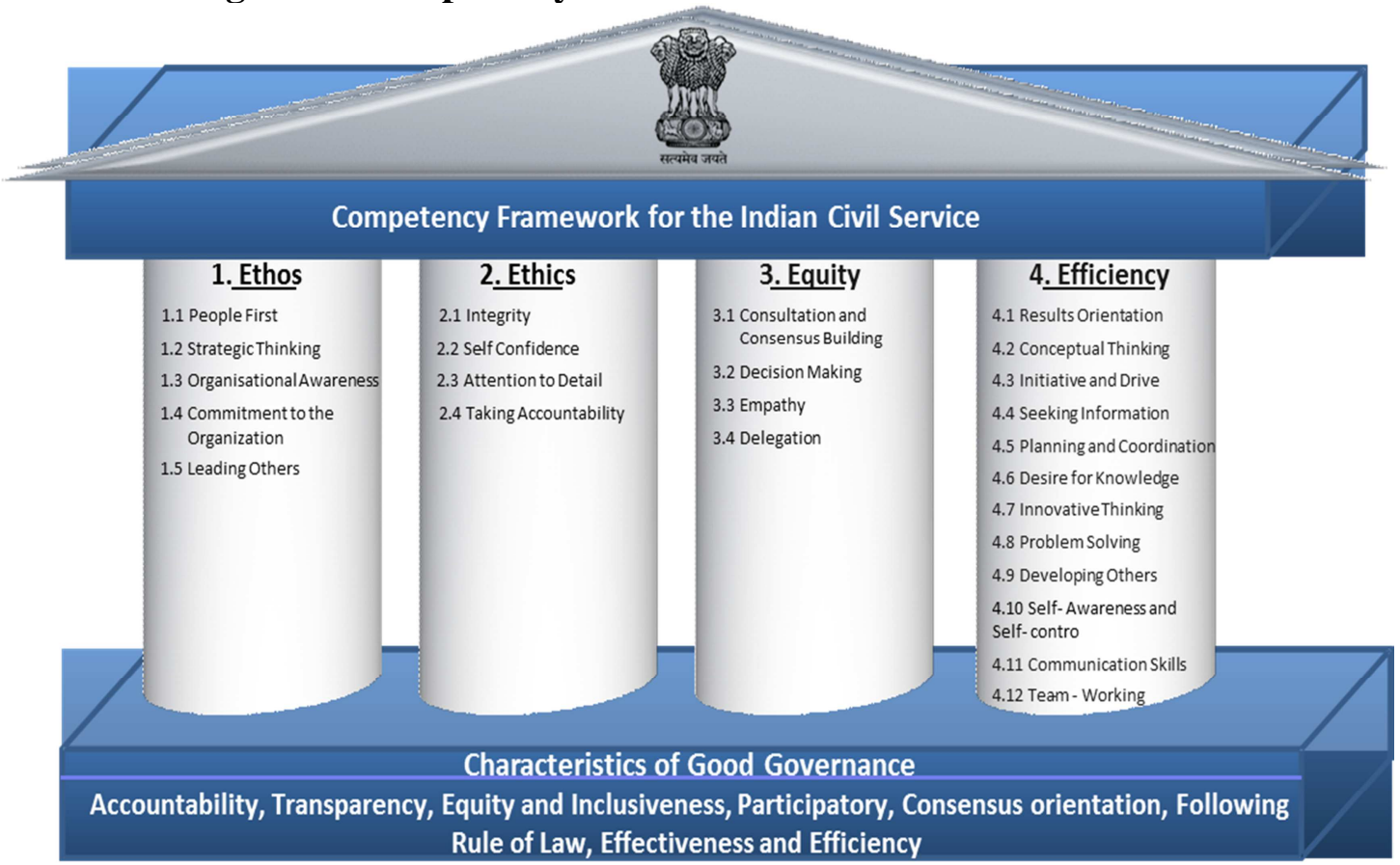

A Competency Dictionary achieves more than simply identifying a set of relevant competencies for a specific organization. Each competency is then defined, proficiency levels within each competency are established, and behavioral indicators for each proficiency level are listed. Using "People First" as an example, these details are depicted in Figure 2 below and illustrate how a Competency Dictionary can become a valuable tool for developing profiles for various jobs or roles in an organization such as the IAS. By definition, the profiles that are developed include details about the knowledge, skills, traits, motives, attitudes, values and other personal characteristics that are needed to drive superior performance in specific jobs or roles. 
Name of the

Competency

Figure 2: Competency Definition, Levels and Indicators

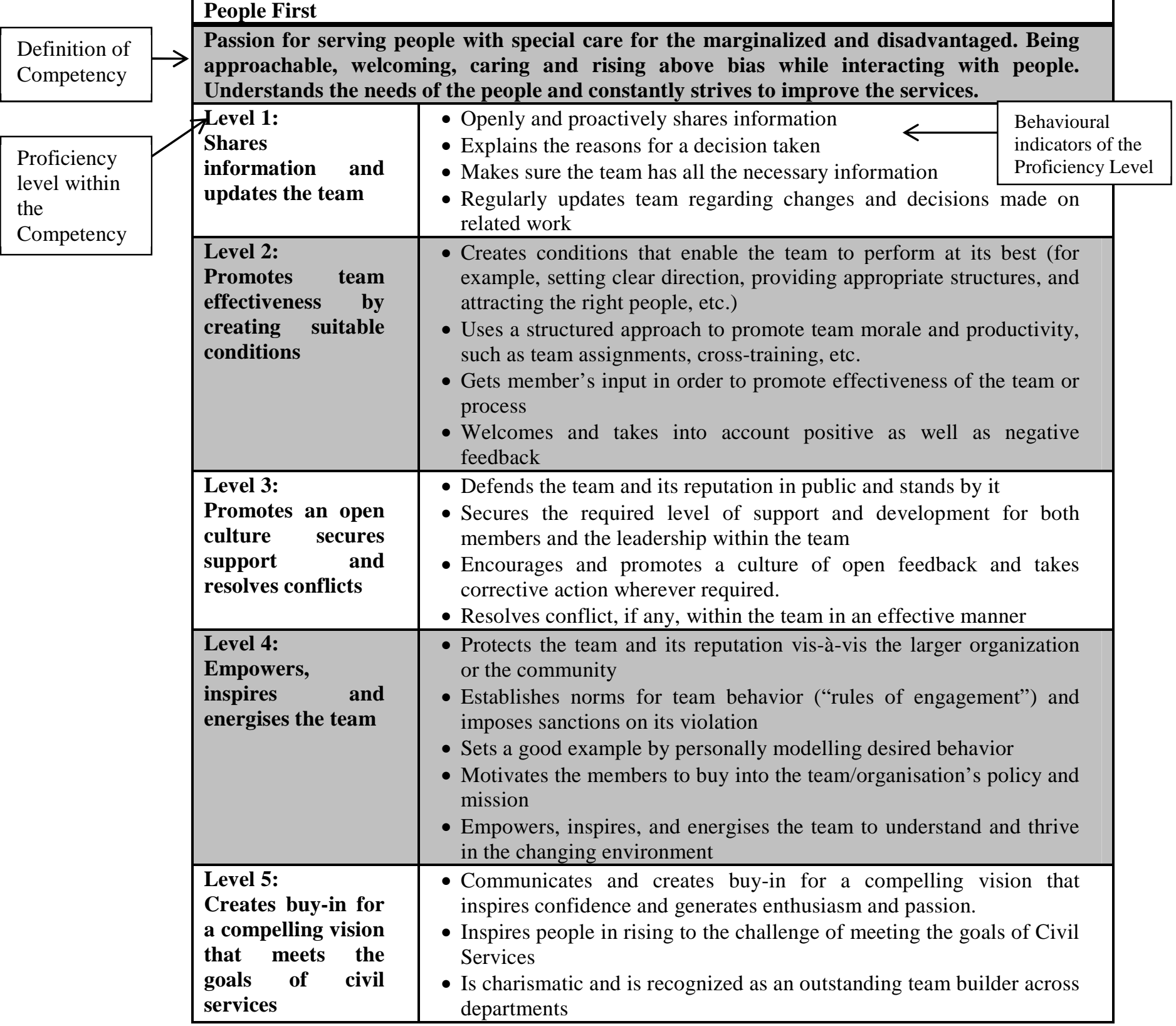

\section{Research Methodology}

The induction training at Academy is focused on the training needs for the positions that officers will hold in their first ten years of service. Upon completing two years induction training, IAS officers are typically posted as Sub-Divisional Magistrates for a year-and-ahalf, then as Additional DM/CEO Zilla Parishad for another 1-2 years, and finally as 
DMs. In the intervening period before being posted as DM, officers may also function as Municipal Commissioner, Deputy Secretary/Director in the state secretariat or chief executive of a public sector undertaking.

A profile of the competencies required for the role of DM was developed and validated by adapting the process described in the Implementation Toolkit ${ }^{7}$. During this process, focus group discussions were conducted and a questionnaire was developed and administered, as detailed below. The assumption underlying this exercise is that clarity about competencies and proficiency levels will help the government to ensure a better fit between the requirements of the role and the competencies of the incumbents. This can be achieved by re-designing the induction training to consciously build the required competencies.

The Competency Dictionary for Civil Services was circulated to all faculty members of the Academy. They were requested to select 8-10 competencies which they feel would be most relevant for becoming an effective DM. It may be noted that Academy faculty members are stakeholders and role holders of this initiative. They are a senior and expert group of civil service officers themselves. Their selection of relevant competencies was based on their own experience as DMs, and their intense interactions with IAS officers frequently in course of the mid-career training programme and other stakeholders such as political leadership, executive leadership, civil society and media.

The process yielded a list of 14 competencies. The 14 competencies were placed in a focus group discussion in November of 2013 to select a final set of 8 core competencies that are the most relevant for success in the DM role. Figure 3 lists the initial 14 competencies and underlines the eight core competencies that have been identified. It may be noted that selection of 8 competencies for achieving success in the role of DM does not imply that the

\footnotetext{
${ }^{7}$ Competency-based Human Resource Management for the Indian Civil Service, Implementation Tool-kit, http://persmin.gov.in/otraining/Implementation\%20Tool-kit.pdf, last accessed June 3, 2014.
} 
other competencies as listed in the dictionary are not important. The exercise only reveals the 8 competencies which are critically required, more than others, for effective performance as a DM.

With respect to the 8 core competencies identified by following the process outlined above, the proficiency levels that are necessary to be an effective DM were subsequently identified. This was done using an online survey among IAS officers with minimum three years in the service i.e., 2010 batch and before. Besides use of social media to seek responses, Chief Secretaries of states were also requested to advise IAS officers to participate in the survey. Questionnaire instructions informed respondents to pick the level of each of the eight competencies which is essential for a DM position. The descriptors for the five levels were jumbled to preclude respondents' tendency to mechanically tick the highest level. ${ }^{8}$ Questionnaire instructions informed participants that "the levels are not in any particular order or sequence" and asked: "that, instead of identifying the highest level of proficiency for each competency, you are requested to pick the one which is essential for a DM." The highest proficiency level is not always useful for profiling a particular role. This is because proficiency levels depend upon the nature of responsibility and the type of challenge given in the stated profile of the role. Annexure-3 of this paper contains the questionnaire.

\footnotetext{
${ }^{8}$ Except for 'Problem Solving' competency, all competencies had five proficiency levels in the competency dictionary. 'Problem Solving' competency had only four proficiency levels. To ensure no confusion to officers responding in our survey - we made this competency also into five proficiency levels (by referring to relevant literature on this competence).
} 
Figure 3: Initial and Final Competencies Identified for the DM Role

\begin{tabular}{|l|l|l|}
\hline \multicolumn{1}{|c|}{ Pillar } & \multicolumn{1}{|c|}{ Definition } & \multicolumn{1}{c|}{ Competencies } \\
\hline 1. Ethos & $\begin{array}{l}\text { Citizen centric and inclusive, } \\
\text { promotes public good and the } \\
\text { long-term interests of the Nation }\end{array}$ & $\begin{array}{l}\text { People First } \\
\text { Leading Others }\end{array}$ \\
\hline 2. Ethics & $\begin{array}{l}\text { Demonstrates integrity, } \\
\text { transparency, openness and } \\
\text { fairness }\end{array}$ & $\begin{array}{l}\text { Self-confidence } \\
\text { Attention to Detail }\end{array}$ \\
\hline 3. Equity & $\begin{array}{l}\text { Treating all citizens alike, } \\
\text { ensuring justice to all, with } \\
\text { empathy for the weaker section }\end{array}$ & $\begin{array}{l}\text { Decision-making } \\
\text { Empathy } \\
\text { Delegation }\end{array}$ \\
\hline 4. Efficiency & $\begin{array}{l}\text { Promoting operational } \\
\text { excellence and value for money, } \\
\text { managing human capital and } \\
\text { nurturing capability }\end{array}$ & $\begin{array}{l}\text { Results Orientation } \\
\text { Initiative and Drive } \\
\text { Planning \& Coordination } \\
\text { Innovative Thinking } \\
\text { Problem Solving } \\
\text { Self-awareness and Self-control }\end{array}$ \\
\hline
\end{tabular}

Over a period of two months, 218 IAS officers responded to the survey. Annexure-4 of this paper gives the profile of the respondents - including the spread batch-wise (see, table A4.1) and the demographic profile (see, table A4.2). It reflects a sample of IAS officers with wide range of experience ranging from officers of the pre-liberalization period to the young generation. The sample median is of officers with a 16-years' experience i.e., officers who have already discharged the role of DM. The cadre profile of the sample reflects that officers from across the country participated in the exercise. The annexure also shows that about $7 \%$ of the officers did not have any prior DM experience (see, table A4.3) - they were largely the officers from recent batches.

Annexure-5 tabulates the results. It also displays the five proficiency levels for each of these eight competencies and the frequency of responses against each one of them (see, tables A5.1 to A5.8). We also present the results of the thematic summary of the qualitative 
responses received (see, part B of the questionnaire) in the same annexure (see, tables A5.9 to A5.11). The next section mulls over the findings and discusses them.

\section{Findings}

\subsection{Profiling the DM's Role from the Findings}

For moving to competency-based approach, it would be necessary to identify the proficiency levels required on each of the eight most relevant competencies for performing duties and responsibilities of a DM. The summarily tabulated responses in Annexure-5 to Part A of the questionnaire gives us a picture of the identified proficiency levels (on each of these competencies) needed to meet the job objectives of DM role (see, tables A5.1 to A5.8). The results on the selected eight competencies obtained after (conducting focus groups and) analyzing questionnaire data gives us a picture of the ideal proficiency levels for these eight competencies needed to meet the job objectives of the DM's role, as presented in Figure 4. 
Figure 4: Competency Profile of an effective DM

\begin{tabular}{|c|c|c|c|}
\hline COMPETENCY & $\begin{array}{c}\text { PROFICIENCY } \\
\text { LEVEL }\end{array}$ & DESCRIPTION & BEHAVIORS \\
\hline $\begin{array}{l}\text { People First (Ethos) } \\
\text { PROMOTES } \\
\text { SERVICE TO THE } \\
\text { CITIZENS }\end{array}$ & Third & $\begin{array}{lr}\text { Redesigns } & \text { and } \\
\text { monitors new } \\
\text { initiatives in public } \\
\text { service delivery, using } \\
\text { technology where } \\
\text { relevant }\end{array}$ & $\begin{array}{l}\text { - Is a role model of positive } \\
\text { community service behaviours } \\
\text { - Promotes a culture focused on } \\
\text { serving and meeting the needs of the } \\
\text { citizens } \\
\text { - Thoroughly explores all the sections } \\
\text { of the community, including the } \\
\text { marginalised and the disadvantaged; } \\
\text { and identifies methods to meet their } \\
\text { needs - including using new } \\
\text { technology where relevant } \\
\text { - Tracks trends that will affect their } \\
\text { own Department's ability to meet } \\
\text { current and future community needs } \\
\text { and continuously strives to provide } \\
\text { effective services to the public } \\
\text { - Focuses their decision making } \\
\text { around the most excluded sections of } \\
\text { the society; and designs and monitors } \\
\text { the execution of these initiatives }\end{array}$ \\
\hline $\begin{array}{l}\text { Leading Others } \\
\text { (Ethos) } \\
\text { ASSUMES } \\
\text { LEADERSHIP }\end{array}$ & Fourth & $\begin{array}{l}\text { Empowers, inspires } \\
\text { and energizes the } \\
\text { team to achieve the } \\
\text { organizational } \\
\text { objectives }\end{array}$ & $\begin{array}{l}\text { - Protects the team and its reputation } \\
\text { vis-à-vis the larger organisation or } \\
\text { the community } \\
\text { - Establishes norms for team behaviour } \\
\text { ("rules of engagement") and imposes } \\
\text { sanctions on its violation } \\
\text { - Sets a good example by personally } \\
\text { modelling desired behaviour } \\
\text { - Motivates the members to buy into } \\
\text { the team/organization's policy and } \\
\text { mission } \\
\text { - Empowers, inspires, and energises } \\
\text { the team to understand and thrive in } \\
\text { the changing environment }\end{array}$ \\
\hline $\begin{array}{l}\text { Integrity (Ethics) } \\
\text { ACTS ETHICALLY }\end{array}$ & First & $\begin{array}{l}\text { Is honest and honors } \\
\text { commitments }\end{array}$ & $\begin{array}{l}\text { - Is open and honest in one's dealings } \\
\text { with others } \\
\text { - Honours commitments made to } \\
\text { others } \\
\text { - Acts in ways to avoid conflict of } \\
\text { interest - perceived or real - for } \\
\text { example -by disclosing potential } \\
\text { issues on time } \\
\text { - Honest and open in all } \\
\text { communications } \\
\text { - Gives frank and honest opinion when } \\
\text { sought } \\
\text { - Follows the rules and regulations and } \\
\text { is guided by Public Service values } \\
\text { - Does not share information loosely } \\
\text { with others }\end{array}$ \\
\hline $\begin{array}{l}\text { Decision-making } \\
\text { (Equity) } \\
\text { MAKES DECISIONS } \\
\text { IN COMPLEX } \\
\text { SITUATIONS }\end{array}$ & Fourth & $\begin{array}{l}\text { Foresees impact of } \\
\text { decisions and relies } \\
\text { on analysis to make } \\
\text { decisions in complex } \\
\text { situations }\end{array}$ & $\begin{array}{l}\text { - Foresees impact of decisions on the } \\
\text { society by conducting social cost- } \\
\text { benefit analysis } \\
\text { - Weighs up competing views to } \\
\text { generate ways forward which will } \\
\text { meet organisational goals }\end{array}$ \\
\hline
\end{tabular}




\begin{tabular}{|c|c|c|c|}
\hline & & & $\begin{array}{l}\text { - Ensures involvement and } \\
\text { consultation of the subject experts } \\
\text { where necessary } \\
\text { - Confidently takes decisions and } \\
\text { clearly communicates at a strategic } \\
\text { level to move things forward }\end{array}$ \\
\hline $\begin{array}{l}\text { *Planning, } \\
\text { Coordination, } \\
\text { Implementation } \\
\text { (Efficiency) } \\
\text { ORGANIZES AND } \\
\text { SCHEDULES OWN } \\
\text { WORK }\end{array}$ & First & $\begin{array}{lr}\text { Uses resources } \\
\text { optimally } & \text { and } \\
\text { manages time well }\end{array}$ & $\begin{array}{l}\text { - Demonstrates good time management } \\
\text { skills to meet short- and medium- } \\
\text { term objectives } \\
\text { - Plans own work schedule and } \\
\text { monitors progress against it } \\
\text { optimally } \\
\text { - Uses available resources optimally to } \\
\text { meet work objective } \\
\text { - Identifies and tries to solve } \\
\text { bottlenecks in own area of work }\end{array}$ \\
\hline $\begin{array}{l}\text { Problem -solving } \\
\text { (Efficiency) } \\
\text { DEVELOPS } \\
\text { SOLUTIONS TO } \\
\text { COMPLEX } \\
\text { PROBLEMS }\end{array}$ & Fifth & $\begin{array}{l}\text { Develops solutions to } \\
\text { complex problems } \\
\text { considering the } \\
\text { medium to long term } \\
\text { impact }\end{array}$ & $\begin{array}{l}\text { - Ability to see the holistic picture } \\
\text { - Identifies interdependencies between } \\
\text { various components } \\
\text { - Communicates complex problems in } \\
\text { a simple manner } \\
\text { - Develops a solution that attempts to } \\
\text { address the complexities at different } \\
\text { levels } \\
\text { - Generates options to address the } \\
\text { problem in its entirety } \\
\text { - Creates solutions that address not } \\
\text { only immediate issues (quick fixes) } \\
\text { but also takes steps for medium to } \\
\text { long-term impact of the solutions }\end{array}$ \\
\hline 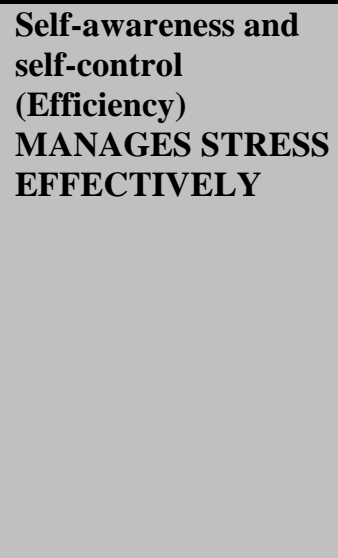 & Third & $\begin{array}{lr}\text { Responds } & \\
\text { constructively } & \text { and } \\
\text { professionally } & \text { under } \\
\text { stress/adversity } & \end{array}$ & $\begin{array}{l}\text { - Actively manages self-effectiveness } \\
\text { in different situations by thoroughly } \\
\text { understanding of one's own } \\
\text { responses } \\
\text { - Uses stress management techniques } \\
\text { to deal with stress and control } \\
\text { responses } \\
\text { - Responds constructively and } \\
\text { professionally to extreme challenges, } \\
\text { provocation and/or professional } \\
\text { disappointments } \\
\text { - Continues providing effective } \\
\text { leadership in situations of stress or } \\
\text { adversity }\end{array}$ \\
\hline $\begin{array}{l}\text { Innovative thinking } \\
\text { (Efficiency) } \\
\text { IS OPEN TO NEW } \\
\text { IDEAS AND } \\
\text { CHANGE }\end{array}$ & First & $\begin{array}{l}\text { Is open to new ideas } \\
\text { and change }\end{array}$ & $\begin{array}{l}\text { - Identifies possibilities of } \\
\text { improvements in current areas of } \\
\text { work } \\
\text { - Open to the possibilities of change } \\
\text { and considers ways to implement and } \\
\text { adapt change in current area of work } \\
\text { - Improvises in case of issues of urgent } \\
\text { importance }\end{array}$ \\
\hline
\end{tabular}

\subsection{Inferences for IAS Induction Training Programme}

We now draw inference on the 2-year IAS induction training programme for the IAS

officers. A majority of the surveyed officers expressed satisfaction on the quality of the 
induction training programme (see table A5.9). In terms of suggested training period, survey finding (see table A5.10) strongly suggests at maintaining status quo with about $80 \%$ of the surveyed officers agreeing to this view. When we combine these findings with the responses for question 4 in part B of the survey questionnaire i.e., table A5.11 and its related thematic analysis in Annexure-5, we observe that the survey respondents suggest pedagogical improvements without proposing major changes. An instance of this comes from table A5.9 wherein over $77 \%$ of officers are rating the existing quality of induction training programme as satisfactory or highly satisfactory.

The minor pedagogical improvements suggested by the 218 surveyed officers can be categorized into four thoughts. They are: (a) have more case-based discussions reflecting practical situations, role plays and audio-video simulations resulting in enhanced understanding and clarity of concepts and regulations. This point gets reflected in table A5.11 throughout; (b) emphasis on collaborative projects involving team work instead of individual efforts. This feature comes out another prime suggestion by the respondents in the thematic analysis (see, table A5.11); (c) increased use of modern technological aids to ensure richer experiential learning. This is one of the key themes emerging from the additional suggestions at the end of table A5.11 wherein, respondents ask for latest features and co-creation with the developed world public administrative training institutes; and (d) mentoring on the field came out as an important aspect in suggestions of table A5.11 for developing seven competencies. Therefore, need for district training of young probationary officer trainees under DMs with good reputation and mentoring abilities is a suggested. This aspect is dwelled in recommendations of both, Ayyar (2007) and Aggrawal (2014) committees.

\subsection{Mapping Competencies with Induction Training Programme}

In the next stage, the identified proficiency-levels for the eight competencies are matched with existing curriculum of the induction training programme and gap(s) in the 
existing curriculum identified. This would ensure alignment of induction training program with the identified generic competencies for the most significant role assigned to an IAS officer in the first ten years of service. We primarily used the recommended and latest work of Lombardo and Eichinger (2009) "For Your Improvement: A Guide Book on Development and Coaching." Along with presenting a comprehensive list and description of competencies needed for leadership, the work presents quick ways of assessing the same along with the training techniques, tools and aids in developing these competencies.

By combining quantitative responses to part I of the survey with qualitative responses to part II of the survey, mining both qualitative and quantitative information - we conclude that induction training of IAS officers needs to be focused towards the following pillars:

(a) Building Effective Teams: The surveyed respondents stressed the importance of building effective teams by selecting 'Level-4' as the desired level for 'Leading Others' competency (see, table A5.2). At 'Level-4', an officer "empowers, inspires and energizes the team to achieve the organizational objectives". This opinion gets further ratified in the suggestions emanating in table A5.11. Building effective teams needs Academy's training to focus on improving communication capabilities, personal and interpersonal skills.

Surveyed IAS officers highlighted the importance of leading change by selecting 'Level-3' as the desired level for 'People First' competency (see, table A5.1). At 'Level3', an officer is expected to "redesign and monitor new initiatives in public service delivery, using technology where relevant". Such initiatives, to be successfully taken forward need a buy-in from not only a small coterie of officials around the IAS officers but also the stakeholders located in very different socio-economic setting. Often, in such challenging situations, the officers also have to influence the organizational work culture. Therefore, we suggest that Academy's training program focus on creating deep seated 
skills and abilities to "Build Effective Teams" and also have role plays and exercises focused on "Leading Change" in young officers. 9 "

(b) Learning through Perseverance: The officers surveyed mentioned the importance of learning to solve complex problems by selecting 'Level-5' as the desired level for 'Problem Solving' competency (see, table A5.6). At 'Level-5', an officer 'develops solutions to complex problems considering the medium to long term impact" - when this is combined with the maximum identified proficiency levels by officers for three other competencies, namely, 'Innovative Thinking' competency (see, table A5.8) signifying “is open to new ideas and change"; 'Planning, Coordination and Implementation' competency (see, table A5.5) suggesting "manages time well”; and 'Self-Awareness and Self-Control" competence (see, table A5.7) indicating "responds constructively and professionally under adversity", it results in need for IAS officers to constantly "learn through perseverance". Given that officers regularly get posted to different assignments, and therein their need to make complex decisions - it only results in further emphasis on the need to develop and nurture this skill.

It would be useful here to refer to the empirical work (Lombardo and Eichinger, 1996) on high-performing leaders by the Center for Creative Leadership. It is popular as “70:20:10 Leadership and Development model." It reveals that: "Lessons learned by successful and effective leaders are roughly: $70 \%$ from tough jobs; $20 \%$ from people (mostly the boss); and 10\% from courses and reading." Seminal work on adult learning Andragogy projects by Allen Tough (1979) is also in agreement and states that 'about $70 \%$ of all learning projects are planned by the learners themselves'. The above affirms the need for careful selection of mentor DMs which would result in useful district training experience for the young officer trainees. District training under the watchful eyes of

\footnotetext{
${ }^{9}$ Refer Ayyar Committee report executive summary page viii and Aggrawal Committee report recommendations page 25
} 
mentor DMs ensures that the young officer trainee would have more effective learning's and would also keep this ability alive in the future. Here, we'd like to revisit one of the corner stone of recent Aggrawal Committee recommendation, participant-centered continuous learning, which validates the above suggestion.

(c) Timely Decision Making: IAS officers with longer tenures as DM are generally perceived as more successful ${ }^{10}$. So, we decided to use "tenure of the responding officers as DM" as a variable for further analysis to seek richer training inputs. On the basis of simple regression analysis ${ }^{11}$, we found that 'Tenure as a $D M$ ' is significantly and positively related to the competency 'Decision Making' (see, table A6.1 in Annexure 6). The statistically significant relation in equation form gets stated as:

Officers Tenure as $\mathbf{D M}=$ Constant $+0.253 \times($ Decision Making $)$

It conveys that IAS officers with higher tenures as DM clearly preferred a higher level of "Decision Making" competency. If we combine this with the majority responses by these respondents for "Self-Awareness and Self-Control" competence at Level-3 (see, table A5.7) i.e., "responds constructively and professionally under stress and adversity", it implies that as officers' tenure increases as a DM, they increasingly realize a need for higher proficiency level of "decision making" competency. Consequently, as an input for the training program, we see the need to focus on building various aspects/steps of managerial decision making, such as: root cause analysis; generation of alternatives; evaluation of alternatives based on criteria (using cost-benefit analysis, impact analysis, resource constraints framework, and such); strategic communication (to teams that will be a part of implementation); and course-correction planning \& implementation. This can be clubbed with developing in-place assignments, long-treks, adventures, and simulations as ideal ways to improve decision making.

\footnotetext{
${ }^{10}$ Baswan B. S. Report on To take a comprehensive look at the requirement of the IAS officers over a longer time frame, Public Grievances and Pensions, Government of India.

${ }^{11}$ An easy summary of the same is placed as correlation matrix in Annedure-6 (see, table A6.1)
} 
(d) High Self-Awareness and Self-Control: We also found that 'Tenure as a DM' is significantly and positively related to the competency 'Self-Analysis and Self-Control' (see, table A6.1 in Annexure 6). Specifically, responding officers with over 4 years of DM tenure had significantly opted for level 5 (highest) need for this competency. The statistically significant relation in equation form gets stated as

\section{Officers Tenure as DM $=$ Constant $+0.157 \times($ Self Awareness and Self Control $)$}

Consequently, as inputs for the training program, we see the need to build the 'selfawareness and self-control' competency of the young IAS officers. Exercises, activities and experiences stressing on increased self-reflection and self-awareness such as Personality Assessments revealing one's inner self in terms of thoughts, emotions, actions, mindset, attitudes and social skills; experiential nature trails such as long adventure treks; co-creation activities; coaching involving active listening and inquiry; and U-journaling can help in developing this competency among the probationary officers.

\subsection{Additional Interpretations}

(e) 'Problem Solving' Competency: The correlation matrix (see, table A6.1) shows another interesting statistically significant relation. We mirror the same in equation form:

\section{Officers Years of Experience $=$ Constant-0.152 x (Problem Solving $)$}

The above equation conveys that as responding officers years of experience i.e., seniority increases, they tend to lessen their, need for 'Problem Solving' competence. Perhaps, the above result could be due to the fact that senior responding officers functioned as DMs in times which preceded liberalization, decentralization and the era of coalition governments. The results indicate that young officers in the contemporary times feel the need to have high levels of Problem Solving competency to develop solutions to complex problem. Accordingly, training inputs of young officers ought to focus more on 
problem solving and managing work processes using exercises and case-simulations hinged on process management, managing through total work systems (such as, TQM/ISO/Sigma) and dealing with ambiguity.

(f) Cluster Analysis: The task of grouping a set of objects (herein responses from surveyed officers) in such a way that objects of same group are more similar to each other than to those in other groups is Clustering. Thus, these are groups with small difference among the cluster members and help us to understand the emerging patterns better. Thus, with such an objective we used a 2-Step cluster analysis on SPSS for the complete data of all the 218 responding officers. It revealed two clusters (see, Annexure 6, table A6.2). We display the size of these clusters along with analytical focus on only those competencies wherein the officers had widely differing responses in Table 5 below:

Table 5: Cluster Sizes for 'Integrity' and 'Leading Others' Competencies

\begin{tabular}{|c|c|c|}
\hline Cluster & $\begin{array}{c}\text { Competence 'Integrity' } \\
\text { Mean Proficiency Level }\end{array}$ & $\begin{array}{c}\text { Competence 'Leading Others' } \\
\text { Mean Proficiency Level }\end{array}$ \\
\hline $\begin{array}{c}\text { Cluster \# 1 } \\
\text { (size of 42\% sample) }\end{array}$ & 3.5 & 2.7 \\
\hline $\begin{array}{c}\text { Cluster \# 2 } \\
\text { (size of 58\% sample) }\end{array}$ & 1.2 & 4.1 \\
\hline
\end{tabular}

As reflected in the table above, the chief difference in these clusters is of the perception about the proficiency levels of 'Integrity' and 'Leading Others' competencies required to successfully performing the role of a DM. Cluster 1 having a size of $42 \%$ of the total responding officers looks forward to relatively higher proficiency levels of "Integrity" competence and lower proficiency levels for "Leading Others" competence compared to Cluster 2 having a size of $58 \%$ of the sample.

Further investigation (see, end of table A6.2) revealed that officers with 'Professional'12 qualification had larger representation in Cluster 2 over Cluster 1. In other words, they preferred a need for higher proficiency level of "Leading Others" competence and lower level

\footnotetext{
${ }^{12}$ Includes the following academic qualifications: B. Tech., BDS, B.E., B.Sc., CA, LLB/LLM, MBA, MBBS, MD
} 
of "Integrity" competence. Further study on this aspect would throw light on the reasons behind such differing opinions. Another instance of difference in responding officer profiles in these two clusters was based on Zone wise distribution. The Zone wise investigation revealed a very strong representation of Central Zone officers (i.e., Chhattisgarh and Madhya Pradesh) in Cluster 1. On the other hand, West and AGMUT Zone officers had a stronger representation in Cluster 2. Future studies on this aspect would throw light on the reasons behind such differing opinions. A third instance of difference came when further data mining was done using Tenure as DM to see the difference. We found that Cluster 2 had relatively more IAS officers with nil and very low experience as DM compared to Cluster 1. These are interesting results and would need further study on this aspect to look into the reasons behind such different proficiency level for the same competence.

Thus, in this section, we focused our efforts on identifying the important learning's emanating from the responses of the 218 IAS officers. First portion of the section focused on the identification of appropriate proficiency levels on the short-listed eight competencies. The second portion of the section dwelled on the implications for the Academy's induction training programme and such research issues. The last section focused on documenting other key empirical findings using few advanced statistical tools.

\section{Conclusions}

Competency consists of deep seated abilities including knowledge, skills and attitudes or behavioral traits. These competencies may be broadly divided into those that are core skills that civil servants would need to possess with different levels of proficiency for different functions at different levels. Some of these core competencies pertain to leadership, financial management, people management, project management and communication. The other set of competencies relate to the professional or specialized skills which are relevant for specialized functions such as building roads, irrigation projects, medical care and such. 
Taking cues from global trends, GoI has decided to move towards a competency-based HRM. This study is an attempt to delve into the competencies to effectively perform the role of District Magistrates (DMs).

At any point of time, there are 600 DMs operating across the country. This practice of developing role-based competencies for IAS officers is a new approach that the Indian government is adopting gradually. In the past, training has generally evolved in a "path dependent" manner which means that the past has, to a large extent, shaped the future. In this research, we use a combination of questionnaire based survey among 218 IAS officers and focus group discussions to identify the proficiency levels needed for the most relevant competencies for an effective DM role. Based on the results, we look at the implications on the induction training programme for the IAS officers.

For moving to a competency-based approach, it would be necessary to identify the required generic competencies for first decade of service of an IAS officer to perform their professional responsibilities effectively. We identify the following eight core competencies as key for performing an effective DM role: People First; Leading Others; Integrity; Decision-Making; Planning, Coordination \& Implementation; Innovative Thinking; Problem Solving; and Self-Awareness and Self-Control. Proficiency levels for each of these eight competencies are also identified. We find that the role demands higher levels of proficiency of the following competencies: Leading Others, Decision Making, Problem Solving, Self-Awareness \& Self-Control and People First.

In the next stage, we use these identified competencies along with their required proficiency levels to identify the implications for Academy's induction training programme. In terms of suggested training pedagogy \& training period, the 218 responding officers surveyed suggest pedagogical improvements to ensure more permanent learning's for effectively performing the role of DM. The research study suggests an increased need for 
case-based discussions, collaborative small group exercises/projects, and district training module with strong mentorship as part of the training pedagogy.

This study has all the limitations of a questionnaire-based research exercise. We list herein the two important ones among them: (a) As many officers were responding long after completion of their DM assignment, they may perhaps not remember all the important aspects of an effective DM role; and (b) As the part A of the questionnaire was standardized so it is possible that some participants may tend to misinterpret a few of the questions. We mitigated this aspect by administering a pilot questionnaire. Also, the responses gathered in a standardized way are more objective, certainly more so than interviews.

This was largely, an exploratory study identifying competencies-required for an effective DM role and their implications on the induction training programme of IAS officers. Further research, both quantitative and qualitative in nature, is required to investigate these initial results on competency-based HRM. This research would add to the growing body of knowledge to ensure a more optimum use of human resources. 


\section{References}

Aggrawal, K. (2014). A Report of the Committee to Review the Content and Duration of Induction Training of IAS Officers. New Delhi: Department of Personnel and Training, Ministry of Personnel, Public Grievances and Pensions, Government of India.

Ayyar, V. V. (2007). Report of the Committee to Review Induction Training Syllabus. New Delhi: Department of Personnel and Training, Ministry of Personnel, Public Grievances and Pensions, Government of India.

Baswan, B. S. (n.d.). Report on To take a comprehensive look at the requirement of the IAS officers over a longer time frame. New Delhi: Department of Personnel and Training, Ministry of Personnel, Public Grievances and Pensions, Government of India.

GoI-UNDP. (2013). Tool-Kit \& Competency Dictionary for Civil Services Officers. Retrieved June 3, 2014, from Ministry of Personnel, Public Grievances and Pensions: http://persmin.gov.in/otraining/CompetencyDictionary.asp

GoI-UNDP. (2013). Strengthening Human Resource Management of Civil Service: Competency-based Human Resource Management for the Indian Civil Service, Service Competency Dictionary for the Civil Services. New Delhi: Department of Personnel and Training, Ministry of Personnel, Public Grievances and Pensions, Government of India. 


\section{$\underline{\text { Annexure-1 }}$}

Profile of the batches:

1.

\begin{tabular}{|c|c|c|c|}
\hline \multicolumn{4}{|c|}{ Gender wise Distribution } \\
\hline Batch Joining Year & FEMALE & MALE & Total \\
\hline $\mathbf{2 0 0 0 - 2 0 0 8}$ & $25.0 \%$ & $75.0 \%$ & $100.0 \%$ \\
\hline $\mathbf{2 0 0 9 - 2 0 1 3}$ & $23.0 \%$ & $77.0 \%$ & $100.0 \%$ \\
\hline
\end{tabular}

Note: (a) Total Batch Size for: Period 2000-2008 is 752; Period 2009-2013 is 605; (b) Percentages have been rounded off to the nearest single decimal figure.

2.

\begin{tabular}{|c|c|c|c|c|}
\hline \multicolumn{5}{|c|}{ Marital status wise Distribution } \\
\hline Batch Joining Year & Engaged & Married & Single & Total \\
\hline $\mathbf{2 0 0 0 - 2 0 0 8}$ & $3.0 \%$ & $22.0 \%$ & $74.0 \%$ & $100.0 \%$ \\
\hline $\mathbf{2 0 0 9 - 2 0 1 3}$ & $4.0 \%$ & $18.0 \%$ & $78.0 \%$ & $100.0 \%$ \\
\hline
\end{tabular}

Note: (a) Total Batch Size for: Period 2000-2008 is 752; Period 2009-2013 is 605; (b) Percentages have been rounded off to the nearest single decimal figure.

3.

\begin{tabular}{|c|c|c|}
\hline \multicolumn{3}{|c|}{ Age Wise Distribution } \\
\hline Age (in Years) $\downarrow \mid$ Batch Joining Year $\rightarrow \mathbf{2 0 0 0 - 2 0 0 8}$ & $\mathbf{2 0 0 9 - 2 0 1 3}$ \\
\hline $\mathbf{2 2 - 2 5}$ & $26.0 \%$ & $29.0 \%$ \\
\hline $\mathbf{2 6 - 2 9}$ & $56.0 \%$ & $52.0 \%$ \\
\hline $\mathbf{3 0 - 3 3}$ & $17.0 \%$ & $18.0 \%$ \\
\hline $\mathbf{3 4 - 3 7}$ & $1.0 \%$ & $1.0 \%$ \\
\hline $\mathbf{3 8 - 4 1}$ & $0 \%$ & $0 \%$ \\
\hline Total & $100 \%$ & $100 \%$ \\
\hline
\end{tabular}

Note: (a) Total Batch Size for: Period 2000-2008 is 752; Period 2009-2013 is 605; (b) Percentages have been rounded off to the nearest single decimal figure.

\begin{tabular}{|c|c|}
\hline \multicolumn{2}{|c|}{ Average Age } \\
\hline $\mathbf{2 0 0 0 - 2 0 0 8}$ & 27.23 \\
\hline $\mathbf{2 0 0 9 - 2 0 1 3}$ & 27.38 \\
\hline
\end{tabular}

4.

\begin{tabular}{|c|c|c|}
\hline \multicolumn{3}{|l|}{ Qualification stream Wise Distribution } \\
\hline Maximum Educational Qualification $\downarrow \mid$ Batch Joining Year $\rightarrow$ & 2000-2008 & 2009-2013 \\
\hline B.Com & $2.4 \%$ & $1.7 \%$ \\
\hline B.Sc. & $10.4 \%$ & $4.8 \%$ \\
\hline B. Tech. & $10.4 \%$ & $19.3 \%$ \\
\hline
\end{tabular}




\begin{tabular}{|l|c|c|}
\hline B.A. & $7.3 \%$ & $7.1 \%$ \\
\hline BDS & $0.9 \%$ & $1.0 \%$ \\
\hline B.E. & $11.4 \%$ & $15.9 \%$ \\
\hline B.V.Sc. & $0.4 \%$ & $1.0 \%$ \\
\hline CA & $1.3 \%$ & $0.3 \%$ \\
\hline LLB & $2.4 \%$ & $3.1 \%$ \\
\hline LLM & $0.7 \%$ & $0.2 \%$ \\
\hline M.Sc. & $6.1 \%$ & $6.0 \%$ \\
\hline M. Tech & $2.5 \%$ & $0.0 \%$ \\
\hline M.A. & $16.4 \%$ & $13.7 \%$ \\
\hline M.B.A. & $4.8 \%$ & $7.1 \%$ \\
\hline M.B.B.S. & $8.8 \%$ & $11.6 \%$ \\
\hline M.Com. & $1.1 \%$ & $1.3 \%$ \\
\hline M.Phil. & $4.9 \%$ & $2.3 \%$ \\
\hline M.V.Sc. & $0.3 \%$ & $0.0 \%$ \\
\hline MCA & $0.1 \%$ & $0.3 \%$ \\
\hline MD & $1.2 \%$ & $0.7 \%$ \\
\hline Others & $4.1 \%$ & $1.8 \%$ \\
\hline Ph.D. & $2.1 \%$ & $0.8 \%$ \\
\hline Total & $100 \%$ & $100 \%$ \\
\hline Note: (a) Th Ba
\end{tabular}

Note: (a) Total Batch Size for: Period 2000-2008 is 752; Period 2009-2013 is 605; (b) Percentages have been rounded off to the nearest single decimal figure.

\begin{tabular}{|c|c|c|}
\hline \multicolumn{3}{|c|}{ Qualification Distribution Summary } \\
\hline MAX_QUAL & $\mathbf{2 0 0 0 - 2 0 0 8}$ & $\mathbf{2 0 0 9 - 2 0 1 3}$ \\
\hline Professional & $50 \%$ & $63 \%$ \\
\hline Academic & $50 \%$ & $37 \%$ \\
\hline
\end{tabular}


IAS

Leadership Development ARCHITECTURE

3. Competency-based

4. Outcome-focused<smiles>C=CC</smiles>

The

Guiding

Principles

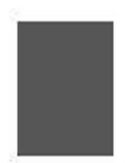

1. Purpose Affirming

$$
1
$$

NATIONAL SERVICE

VALUES

2. Multi-Stakeholder -

"individual-tailored"

I

5. Comprehensive - "hire to refire

I

7. Aspirational -

"Globally Benchmarked - Best in Class" 


\section{Annexure-3: Questionnaire}

\section{COMPETENCY LEVELS REQUIRED OF AN EFFECTIVE DISTRICT MAGISTRATE}

The purpose of this questionnaire is to conduct a survey to ascertain the levels of critical competencies required to be an effective DM. In course of research, it has emerged that more than knowledge and skills, proficiency in certain competencies result in effective and/or superior performance in a role. While knowledge and skills are the most common means of matching people to jobs, it is important to note that rarely do they differentiate performance. More often, they represent the baseline requirements for a job. Excellence usually depends on the more deep-seated characteristics of the officer - motive, trait, aspects of one's social image, social goal. Competencies are hence defined as underlying behaviours necessary to the achievement of a desired outcome.

An exercise has been taken up at the Academy to identify the critical competencies which are required to become an effective DM. As a result, eight competencies have been identified as follows:

\begin{tabular}{|c|c|}
\hline Competency & Definition \\
\hline 1. People First & $\begin{array}{l}\text { Passion for serving people with special care for the marginalized and } \\
\text { disadvantaged. Being approachable, welcoming, caring and rising } \\
\text { above bias while interacting with people. Understands the needs of the } \\
\text { people and constantly strives to improve the services. }\end{array}$ \\
\hline 2. Leading Others & Ability to engage, energise, and enable the team to excel. \\
\hline 3. Integrity & $\begin{array}{l}\text { Consistently behaves in an open, fair and transparent manner, honors } \\
\text { one's commitments and works to uphold the Public service values. }\end{array}$ \\
\hline 4. Decision Making & $\begin{array}{l}\text { Makes timely decisions that takes into account relevant facts, tasks, } \\
\text { goals, constraints, risk and conflicting points of view }\end{array}$ \\
\hline $\begin{array}{l}\text { 5. Planning and } \\
\text { Coordination }\end{array}$ & $\begin{array}{l}\text { Ability to plan, organise and monitor work with effective utilisation of } \\
\text { resources such as time, money, and people }\end{array}$ \\
\hline 6. Problem Solving & $\begin{array}{l}\text { Understanding a situation by breaking it into small parts, organising } \\
\text { information systematically and setting priorities }\end{array}$ \\
\hline $\begin{array}{l}\text { 7. Self-Awareness } \\
\text { and Self-Control }\end{array}$ & $\begin{array}{l}\text { Identifies one's own emotional triggers and controls one's emotional } \\
\text { responses. Maintains sense of professionalism and emotional restraint } \\
\text { when provoked, faced with hostility or working under increased } \\
\text { stress. It includes resilience and stamina despite prolonged adversities }\end{array}$ \\
\hline $\begin{array}{l}\text { 8. Innovative } \\
\text { Thinking }\end{array}$ & $\begin{array}{l}\text { Open to change, approaches issues differently, offers alternate / out of } \\
\text { box solutions and strives for efficiency by working smartly }\end{array}$ \\
\hline
\end{tabular}

In course of this survey we would like to identify the proficiency level within each competency which is required of an IAS officer to be an effective DM. Since the two year induction training programme of IAS officers at Academy is basically targeted to equip them for the first eight years of service (during which they would also function as DM), we intend to use the findings to identify the gap(s) in our training curriculum.

Against the eight competencies listed in this questionnaire, five proficiency levels each are given out of which you need to select the one which is most required of a DM. Please note that the levels are not in any particular order or sequence. A DM to be effective need not exhibit the highest level proficiency in respect of each competency as the level 
depends upon the position and responsibility. Hence, instead of identifying the highest level of proficiency for each competency, you are requested to pick the one which is essential for a DM.

\section{Questionnaire}

Name:

Batch:

Age:

Cadre:

Basic Qualification:

Duration of posting as DM: (Nil, <1 yr, 1-2 yrs, 2-3yrs, 3-4 yrs, 4-5 yrs, >5 yrs)

\section{Part I}

Eight Competencies with five levels each are given below. You are requested to choose only one of the five levels which is critically required to be an effective DM.

\section{People First}

Redesigns and monitors new initiatives in public service delivery, using technology where relevant

Understands issues from citizens' perspective and seeks feedback to improve service

Responds with speed and sensitivity to the needs of citizens, particularly marginalized

Sets public service standards and systems to improve public services

Tracks global trends, develops service delivery strategy and a citizen-centric culture

\section{Leading Others}

Creates appropriate structures to promote team effectiveness

Creates buy-in for a compelling vision that meets the goals of civil services

Shares information and updates the team

Empowers, inspires and energizes the team to thrive in the changing environment

Promotes an open culture, secures support and resolves conflicts

\section{Integrity}

Acts as a role model and creates an open, honest and ethical culture

Is unflinching on public service values in spite of extraneous pressure.

Has the conviction to make and stand by decisions in public interest even at personal cost

Is guided by public interest in conflicting situations

Is honest and honours commitments

\section{Decision Making}

Demonstrates decisiveness when under pressure or faced with uncertainty and/or limited information

Makes long-term strategic decisions in interest of the society

Foresees impact of decisions and relies on analysis to make decisions in complex situations

In case of ambiguity, gathers information/new data for decision making

Makes timely decisions based on applicable rules 


\section{Planning, Coordination and Implementation}

Balances the priorities of the different interest groups to achieve sustainable solutions Creates a long-term planning focus to enable the organization to reach its potential Uses resources optimally and manages time well Monitors own progress and makes timely adjustments to workplan, when required Prioritizes multiple, interrelated tasks, anticipates and manages risks

\section{Problem Solving}

Breaks down complex issues into smaller parts for easier analysis of the root cause Develops solutions to complex problems considering the medium to long term impact Organizes information systematically in order to identify critical problems Identifies cause and effect relationship between two aspects of a problem and weighs pros and cons Identifies multiple cause and effect relationships, develops options and mitigates risk

\section{Self-Awareness and Self-Control}

Diffuses stressful situations and coaches/mentors others on ways to manage stress Is aware of self and listens to others' point of view Responds constructively and professionally under stress/adversity Manages emotional impulses and acts calmly in difficult situations Nurtures a culture of rationality and emotional maturity in the organization

\section{Innovative Thinking}

Applies learning from experience and identifies possible areas of improvement Creates a culture of innovation, mobilizing the organizational resources to engineer change

Is open to new ideas and change

Encourages 'out-of-the-box' solutions and puts in place mechanisms to manage change

Proactively engages with stakeholders to effect continuous improvement in service

\section{Part II}

We are also in the process of revisiting the course curriculum of the 2-year induction training programme. You are also requested to respond to the following questions which would help us to better design the induction training.

1. Please rate the quality of induction training imparted at Academy on a scale of 1 to 5: 1 being least satisfactory and 5 being highly satisfactory

2. What are your views regarding the duration of the 2-year induction training at Academy?
a. Should be reduced
b. Just right
c. Should be increased 
3. Please mention the aspect(s) of training at Academy which were found highly useful by you to function as a DM.

4. Please suggest if there are any specific inputs that you feel must be incorporated in the curriculum of induction training programme to build up the required competencies

\begin{tabular}{|l|l|}
\hline People First & \\
\hline Leading Others & \\
\hline Integrity & \\
\hline Decision Making & \\
\hline $\begin{array}{l}\text { Planning and } \\
\text { Coordination }\end{array}$ & \\
\hline Problem Solving & \\
\hline $\begin{array}{l}\text { Self-Awareness } \\
\text { and Self-Control }\end{array}$ & \\
\hline $\begin{array}{l}\text { Innovative } \\
\text { Thinking }\end{array}$ & \\
\hline
\end{tabular}


Table A4.1 Batch of the Responding IAS Officers

\begin{tabular}{|c|c|c|}
\hline $\begin{array}{c}\text { Batch of the Responding } \\
\text { Officer (in Intervals) }\end{array}$ & Frequency & Percent \\
\hline $\mathbf{1 9 6 1 - 1 9 6 5}$ & 1 & 0.5 \\
\hline $\mathbf{1 9 7 1 - 1 9 7 5}$ & 3 & 1.4 \\
\hline $\mathbf{1 9 7 6 - 1 9 8 0}$ & 3 & 1.4 \\
\hline $\mathbf{1 9 8 1 - 1 9 8 5}$ & 22 & 10.1 \\
\hline $\mathbf{1 9 8 6 - 1 9 9 0}$ & 7 & 3.2 \\
\hline $\mathbf{1 9 9 1 - 1 9 9 5}$ & 26 & 11.9 \\
\hline $\mathbf{1 9 9 6 - 2 0 0 0}$ & 34 & 15.6 \\
\hline $\mathbf{2 0 0 1 - 2 0 0 5}$ & 78 & 35.8 \\
\hline $\mathbf{2 0 0 6 - 2 0 1 0}$ & 44 & 20.1 \\
\hline Total & $\mathbf{2 1 8}$ & $\mathbf{1 0 0 . 0 0}$ \\
\hline
\end{tabular}

Table A4.2 Cadre of the Responding IAS Officers

\begin{tabular}{|l|c|c|}
\hline \multicolumn{1}{|c|}{ Cadre } & Frequency & Percent \\
\hline AGMUT & 9 & 4.1 \\
\hline Andhra Pradesh & 12 & 5.5 \\
\hline Assam-Meghalaya & 6 & 2.8 \\
\hline Bihar & 8 & 3.7 \\
\hline Chhattisgarh & 7 & 3.2 \\
\hline Gujarat & 4 & 1.8 \\
\hline Haryana & 9 & 4.1 \\
\hline Himachal Pradesh & 2 & .9 \\
\hline Jammu \& Kashmir & 6 & 2.8 \\
\hline Jharkhand & 10 & 4.6 \\
\hline Karnataka & 4 & 1.8 \\
\hline Kerala & 5 & 2.3 \\
\hline Madhya Pradesh & 13 & 6.0 \\
\hline Maharashtra & 18 & 8.3 \\
\hline Manipur-Tripura & 9 & 4.1 \\
\hline Nagaland & 2 & .9 \\
\hline Orissa & 7 & 3.2 \\
\hline Punjab & 12 & 5.5 \\
\hline Rajasthan & 12 & 5.5 \\
\hline Sikkim & 4 & 1.8 \\
\hline Tamil Nadu & 11 & 5.0 \\
\hline Uttar Pradesh & 34 & 15.6 \\
\hline Uttarakhand & 3 & 1.4 \\
\hline West Bengal & 11 & 5.0 \\
\hline Total & $\mathbf{2 1 8}$ & $\mathbf{1 0 0 . 0 0}$ \\
\hline
\end{tabular}


Table A4.3 Duration of the Posting as DM of the Responding IAS Officers

\begin{tabular}{|l|c|c|}
\hline Duration in years & Frequency & Percentage \\
\hline NIL & 16 & 7.3 \\
\hline < 1 year & 35 & 16.1 \\
\hline 1-2 years & 41 & 18.8 \\
\hline 2-3 years & 39 & 17.9 \\
\hline 3-4 years & 22 & 10.1 \\
\hline More than 4 years & 65 & 29.8 \\
\hline Total & $\mathbf{2 1 8}$ & $\mathbf{1 0 0 . 0 0}$ \\
\hline
\end{tabular}

\section{Annedure-5: Tabulated Survey Responses}

We describe the five levels for each of the eight competencies below along with the tabulated responses of the officers surveyed:

$\underline{\text { Table A5.1 Identified Proficiency Level Needed for 'People First' Competency by }}$ Responding IAS Officers

\begin{tabular}{|c|l|c|c|}
\hline Level & \multicolumn{1}{|c|}{ Description } & Frequency & Percent \\
\hline $\mathbf{1}$ & $\begin{array}{l}\text { Responds with speed and sensitivity to the needs of citizens, } \\
\text { particularly marginalized }\end{array}$ & 26 & 11.9 \\
\hline $\mathbf{2}$ & $\begin{array}{l}\text { Understands issues from citizens' perspective and seeks } \\
\text { feedback to improve service }\end{array}$ & 54 & 24.8 \\
\hline $\mathbf{3}$ & $\begin{array}{l}\text { Redesigns and monitors new initiatives in public service } \\
\text { delivery, using technology where relevant }\end{array}$ & 80 & 36.7 \\
\hline $\mathbf{4}$ & $\begin{array}{l}\text { Sets public service standards and systems to improve public } \\
\text { services }\end{array}$ & 42 & 19.3 \\
\hline $\mathbf{5}$ & $\begin{array}{l}\text { Tracks global trends, develops service delivery strategy and a } \\
\text { citizen-centric culture }\end{array}$ & 16 & 7.3 \\
\hline & \multicolumn{1}{|c|}{ Total Responses $\rightarrow$} & $\mathbf{2 1 8}$ & $\mathbf{1 0 0 . 0}$ \\
\hline
\end{tabular}

Table A5.2 Identified Proficiency Level Needed for 'Leading Others' Competency by Responding IAS Officers

\begin{tabular}{|c|l|c|c|}
\hline Level & \multicolumn{1}{|c|}{ Description } & Frequency & Percent \\
\hline $\mathbf{1}$ & Shares information and updates the team & 34 & 15.6 \\
\hline $\mathbf{2}$ & Creates appropriate structures to promote team effectiveness & 10 & 4.6 \\
\hline $\mathbf{3}$ & $\begin{array}{l}\text { Promotes an open culture, secures support and resolves } \\
\text { conflicts }\end{array}$ & 4 & 1.8 \\
\hline $\mathbf{4}$ & $\begin{array}{l}\text { Empowers, inspires and energizes the team to achieve the } \\
\text { organizational objectives }\end{array}$ & 151 & 69.3 \\
\hline $\mathbf{5}$ & $\begin{array}{l}\text { Creates buy-in for a compelling vision that meets the goals of } \\
\text { the civil services }\end{array}$ & 19 & 8.7 \\
\hline & \multicolumn{1}{|c|}{ Total Responses $\rightarrow$} & $\mathbf{2 1 8}$ & $\mathbf{1 0 0 . 0}$ \\
\hline
\end{tabular}


Table A5.3 Identified Proficiency Level Needed for 'Integrity' Competency by Responding IAS Officers

\begin{tabular}{|c|l|c|c|}
\hline Level & \multicolumn{1}{|c|}{ Description } & Frequency & Percent \\
\hline $\mathbf{1}$ & Is honest and honors commitments & 124 & 56.9 \\
\hline $\mathbf{2}$ & Is guided by public interest in conflicting situations & 31 & 14.2 \\
\hline $\mathbf{3}$ & $\begin{array}{l}\text { Has the conviction to make and stand by decisions in } \\
\text { public interest even at personal cost }\end{array}$ & 17 & 7.8 \\
\hline $\mathbf{4}$ & $\begin{array}{l}\text { Is unflinching on public service values in spite of } \\
\text { extraneous pressure }\end{array}$ & 0 & 0 \\
\hline $\mathbf{5}$ & $\begin{array}{l}\text { Acts as a role model and creates an open, honest and } \\
\text { ethical culture }\end{array}$ & $\mathbf{1}$ & 21.1 \\
\hline & \multicolumn{1}{|c|}{ Total Responses $\rightarrow$} & $\mathbf{1 0 0 . 0}$ \\
\hline
\end{tabular}

Table A5.4 Identified Proficiency Level Needed for 'Decision Making' Competency by Responding IAS Officers

\begin{tabular}{|c|l|c|c|}
\hline Level & \multicolumn{1}{|c|}{ Description } & Frequency & Percent \\
\hline $\mathbf{1}$ & Makes timely decisions based on applicable rules & 27 & 12.4 \\
\hline $\mathbf{2}$ & $\begin{array}{l}\text { In case of ambiguity, gathers information/new data for } \\
\text { decision making }\end{array}$ & 52 & 23.9 \\
\hline $\mathbf{3}$ & $\begin{array}{l}\text { Demonstrates decisiveness when under pressure or faced } \\
\text { with uncertainty and/ or limited information }\end{array}$ & 47 & 21.6 \\
\hline $\mathbf{4}$ & $\begin{array}{l}\text { Foresees impact of decisions and relies on analysis to make } \\
\text { decisions in complex situations }\end{array}$ & 86 & 39.4 \\
\hline $\mathbf{5}$ & Makes long-term strategic decisions in interest of the society & 6 & 2.8 \\
\hline & \multicolumn{1}{|c}{ Total Responses $\rightarrow$} & $\mathbf{2 1 8}$ & $\mathbf{1 0 0 . 0}$ \\
\hline
\end{tabular}

Table A5.5 Identified Proficiency Level Needed for 'Planning, Coordination and Implementation' Competency by Responding IAS Officers

\begin{tabular}{|c|l|c|c|}
\hline Level & \multicolumn{1}{|c|}{ Description } & Frequency & Percent \\
\hline $\mathbf{1}$ & Uses resources optimally and manages time well & 70 & 32.1 \\
\hline $\mathbf{2}$ & $\begin{array}{l}\text { Monitors own progress and makes timely adjustments to } \\
\text { work plan, when required }\end{array}$ & 42 & 19.3 \\
\hline $\mathbf{3}$ & $\begin{array}{l}\text { Prioritizes multiple, interrelated tasks, anticipates and } \\
\text { manages risks }\end{array}$ & 28 & 12.8 \\
\hline $\mathbf{4}$ & $\begin{array}{l}\text { Balances the priorities of the different interest groups to } \\
\text { achieve sustainable solutions }\end{array}$ & 57 & 26.1 \\
\hline $\mathbf{5}$ & $\begin{array}{l}\text { Creates a long-term planning focus to enable the organization } \\
\text { to reach its potential }\end{array}$ & 21 & 9.6 \\
\hline & \multicolumn{1}{|c}{ Total Responses $\rightarrow$} & $\mathbf{2 1 8}$ & $\mathbf{1 0 0 . 0}$ \\
\hline
\end{tabular}


Table A5.6 Identified Proficiency Level Needed for 'Problem Solving' Competency by Responding IAS Officers

\begin{tabular}{|c|l|c|c|}
\hline Level & \multicolumn{1}{|c|}{ Description } & Frequency & Percent \\
\hline $\mathbf{1}$ & $\begin{array}{l}\text { Organizes information systematically in order to identify } \\
\text { critical problems }\end{array}$ & 26 & 11.9 \\
\hline $\mathbf{2}$ & $\begin{array}{l}\text { Breaks down complex issues into smaller parts for easier } \\
\text { analysis of the root cause }\end{array}$ & 25 & 11.5 \\
\hline $\mathbf{3}$ & $\begin{array}{l}\text { Identifies cause and effect relationship between two aspects } \\
\text { of the problem and weighs pros and cons }\end{array}$ & 53 & 24.3 \\
\hline $\mathbf{4}$ & $\begin{array}{l}\text { Identifies multiple cause and effect relationships, develops } \\
\text { options and mitigates risk }\end{array}$ & 35 & 16.1 \\
\hline $\mathbf{5}$ & $\begin{array}{l}\text { Develops solutions to complex problems considering the } \\
\text { medium to long term impact }\end{array}$ & 79 & 36.2 \\
\hline & \multicolumn{1}{|c}{ Total Responses $\rightarrow$} & $\mathbf{2 1 8}$ & $\mathbf{1 0 0 . 0}$ \\
\hline
\end{tabular}

Table A5.7 Identified Proficiency Level Needed for 'Self-Awareness and Self-Control' Competency by Responding IAS Officers

\begin{tabular}{|c|c|c|c|}
\hline Level & Description & Frequency & Percent \\
\hline 1 & Is aware of self and listens to others' point of view & 52 & 23.9 \\
\hline 2 & $\begin{array}{l}\text { Manages emotional impulses and acts calmly in difficult } \\
\text { situations }\end{array}$ & 25 & 11.5 \\
\hline 3 & $\begin{array}{l}\text { Responds constructively and professionally under } \\
\text { stress/adversity }\end{array}$ & 62 & 28.4 \\
\hline 4 & $\begin{array}{l}\text { Diffuses stressful situations and coaches/mentors others on } \\
\text { ways to manage stress }\end{array}$ & 35 & 16.1 \\
\hline$\overline{5}$ & $\begin{array}{l}\text { Nurtures a culture of rationality and emotional maturity in } \\
\text { the organization }\end{array}$ & 44 & 20.2 \\
\hline & Total Responses $\rightarrow$ & 218 & 100.0 \\
\hline
\end{tabular}

Table A5.8 Identified Proficiency Level Needed for 'Innovative Thinking' Competency by Responding IAS Officers

\begin{tabular}{|c|l|c|c|}
\hline Level & \multicolumn{1}{|c|}{ Description } & Frequency & Percent \\
\hline $\mathbf{1}$ & Is open to new ideas and change & 60 & 27.5 \\
\hline $\mathbf{2}$ & $\begin{array}{l}\text { Applies learning from experience and identifies possible } \\
\text { areas of improvement }\end{array}$ & 31 & 14.2 \\
\hline $\mathbf{3}$ & $\begin{array}{l}\text { Proactively engages with stakeholders to effect continuous } \\
\text { improvement in service }\end{array}$ & 50 & 22.9 \\
\hline $\mathbf{4}$ & $\begin{array}{l}\text { Encourages out-of-the-box' solutions and puts in place } \\
\text { mechanisms to manage change }\end{array}$ & 38 & 17.4 \\
\hline $\mathbf{5}$ & $\begin{array}{l}\text { Creates a culture of innovation, mobilizing the organizational } \\
\text { resource to engineer change }\end{array}$ & 39 & 17.9 \\
\hline & \multicolumn{1}{|c|}{ Total Responses $\rightarrow$} & $\mathbf{2 1 8}$ & $\mathbf{1 0 0 . 0}$ \\
\hline
\end{tabular}


We tabulate below the responses on the quality and duration of the induction training imparted for the IAS officers i.e., part II of questionnaire.

Table A5.9 Rating on the Quality of the Induction Training Programme at Academy by Responding IAS Officers

\begin{tabular}{|c|c|c|}
\hline Rating on the Quality of the Induction Training Program & Frequency & Percent \\
\hline Highly Unsatisfactory & 4 & 2.1 \\
\hline Unsatisfactory & 14 & 7.4 \\
\hline Neither Unsatisfactory Nor Satisfactory & 24 & 12.8 \\
\hline Satisfactory & 122 & 64.9 \\
\hline Highly Satisfactory & 24 & 12.8 \\
\hline Total Responses Received $\rightarrow$ & 188 & 100.0 \\
\hline
\end{tabular}

Table A5.10 Views Regarding the Duration of the 2-years Induction Training Programme at Academy by Responding IAS Officers

\begin{tabular}{|c|c|c|}
\hline Views regarding the duration of the 2-year induction training & Frequency & Percent \\
\hline Should be Reduced & 39 & 20.7 \\
\hline Just Right & 141 & 75.0 \\
\hline Should be Increased & 8 & 4.3 \\
\hline Total Responses Received $\rightarrow$ & 188 & 100.0 \\
\hline
\end{tabular}

In DM survey, we also focused on identifying the strengths and areas of improvement of the current training program at Academy. We provide below the summary of the Thematic Analysis of Questions 3-5 of the Part-B of the Questionnaire:

In order to evaluate the practical utility of training at Academy, participants of the DM survey were asked to list down the aspects of training that were useful for them (refer to question 3). All the responses were carefully analyzed (using content analysis technique) and categorized under various themes. Broadly, feedback was provided in three areas: a) course content; b) methodology; and c) personal development initiatives.

Majority of respondents (55\%) found 'Course Content' useful for their job execution. Second most liked (37\%) element of Academy training was 'Methodology'. And, a few respondents (8\%) considered 'Personal Development Initiatives' during Academy training as useful for shaping a good career. We will highlight various components within these three areas. 


\section{A. Course Content}

Out of 72 respondents who rated 'Course Content' of Academy training as useful, majority liked the content of courses on 'Law \& Order, Indian Constitution. The next in order were the 'Management Concepts' and 'Public Administration Concepts'.

\section{B. Methodology}

Out of 49 respondents who admired the 'Methodology' of Academy training, 31 liked the focus on 'Experiential Learnings' (especially, Bharat Darshan) and 18 liked the usage of 'Contemporary Methods' \& 'Case Studies' in training.

\section{Personal Development Initiatives}

Respondents also found the 'process of shaping an individual' useful for a successful career. Specifically, 4 respondents found 'Focus on Time Management \& Punctuality' useful, while 3 respondents admired the focus on 'Physical Fitness'. Extra attention given on learning the 'Cadre Language' and 'Shaping the Right Attitude' was also admired by 3 respondents.

Respondents were also asked about the ways in which the eight selected leadership competencies can further developed through induction training (refer to question 4 of Part-B of the questionnaire). On the basis of thematic content analysis, following inferences were drawn:

Table A5.11: Suggested Ways of Building the Eight Critical Leadership Competencies

\begin{tabular}{|l|l|}
\hline \multicolumn{1}{|c|}{ COMPETENCIES } & \multicolumn{1}{|c|}{ MOST RELEVANT SUGGESTIONS } \\
\hline PEOPLE FIRST & $\begin{array}{l}\text { 1. Exposure \& Reflection approach (exposure to poor/needy } \\
\text { sections of the society; interactions with NGOs or officers } \\
\text { working with similar sections; and self-reflection) } \\
\text { 2. Experience sharing by senior officers (focus on the } \\
\text { importance of people aspects) } \\
\text { 3. Exposure to public grievance redressal (e.g. Janta Darbars) } \\
\text { 4. Field level interactions with farmers, artisans, small } \\
\text { entrepreneurs, marginalized sections, etc. }\end{array}$ \\
\hline LEADING OTHERS & 1. Team based exercises, simulations, and assignments \\
\hline
\end{tabular}




\begin{tabular}{|c|c|}
\hline & $\begin{array}{l}\text { including practical hands on exposure } \\
\text { 2. Mentoring by senior officers or people known with } \\
\text { leadership skills } \\
\text { 3. Case study approach } \\
\text { 4. Experience sharing/ guest lectures } \\
\text { 5. Dedicated leadership development modules }\end{array}$ \\
\hline INTEGRITY & $\begin{array}{l}\text { 1. Role play (focus on decision making with integrity under } \\
\text { stress) } \\
\text { 2. Case study approach } \\
\text { 3. Training module on Ethics and Values } \\
\text { 4. Build awareness on legal framework against dishonesty } \\
\text { 5. Experience sharing (guest lectures, mentoring, etc.) } \\
\text { 6. Spiritual sessions (yoga, guest lectures by eminent spiritual } \\
\text { leaders) }\end{array}$ \\
\hline DECISION MAKING & $\begin{array}{l}\text { 1. Enhance risk taking ability \& time bound unambiguous } \\
\text { decision making abilities using training } \\
\text { 2. Awareness on decision making frameworks (stakeholder } \\
\text { analysis and consultation, feedback, contingency planning, } \\
\text { cost-benefit analysis, evaluation techniques, etc.) } \\
\text { 3. Case studies incorporating minutes of meeting wherein vital } \\
\text { decisions were taken } \\
\text { 4. Role plays } \\
\text { 5. Learning through experience (projects, field-assignments, } \\
\text { etc.) } \\
\text { 6. Training on brainstorming and participative decision making }\end{array}$ \\
\hline $\begin{array}{l}\text { PLANNING, } \\
\text { COORDINATION, \& } \\
\text { IMPLEMENTATION }\end{array}$ & $\begin{array}{l}\text { 1. Training on basic concepts \& tools including management } \\
\text { information systems (MIS) and such IT based tools } \\
\text { 2. Exercises/field-assignments } \\
\text { 3. Simulations } \\
\text { 4. Role plays } \\
\text { 5. Cases studies } \\
\text { 6. Team building exercises }\end{array}$ \\
\hline PROBLEM SOLVING & $\begin{array}{l}\text { 1. Case study approach, class room mock drills, } \\
\text { 2. Problem analysis going to the minutest of all details, } \\
\text { identifying root causes and responding } \\
\text { 3. Field-assignments } \\
\text { 4. Expert sessions }\end{array}$ \\
\hline $\begin{array}{l}\text { SELF-AWARENESS \& } \\
\text { CONTROL }\end{array}$ & $\begin{array}{l}\text { 1. Spiritual sessions (Yoga, meditation, and other techniques } \\
\text { of inner exploration and healing) } \\
\text { 2. Training on Emotional Intelligence } \\
\text { 3. Case study approach } \\
\text { 4. Personal counseling (individual focus and development) } \\
\text { 5. Sessions on 'Dynamics of Human Behaviour' }\end{array}$ \\
\hline $\begin{array}{l}\text { INNOVATIVE } \\
\text { THINKING }\end{array}$ & $\begin{array}{l}\text { 1. Case based approach } \\
\text { 2. Expert sessions by innovators } \\
\text { 3. Session on 'innovations in public service' to share } \\
\text { international experiences } \\
\text { 4. Group discussion/exercises (focus on generating innovative } \\
\text { ideas on any public service initiative/case) } \\
\text { 5. Share best practices from other countries }\end{array}$ \\
\hline
\end{tabular}


Annexure 6: Key Findings Using Advanced Statistical Tools

Table A6.1: Correlation Matrix for Responses by all the 218 Surveyed Officers

\begin{tabular}{|c|c|c|c|c|c|c|c|c|c|c|}
\hline & $\begin{array}{c}\text { DM } \\
\text { Tenure }\end{array}$ & $\begin{array}{c}\text { Officers } \\
\text { Years of } \\
\text { Experience }\end{array}$ & $\begin{array}{c}\text { People } \\
\text { First }\end{array}$ & $\begin{array}{c}\text { Leading } \\
\text { Others }\end{array}$ & Integrity & $\begin{array}{l}\text { Decision } \\
\text { Making }\end{array}$ & $\begin{array}{c}\text { Planning, } \\
\text { Coordination \& } \\
\text { Implementation }\end{array}$ & $\begin{array}{c}\text { Problem } \\
\text { Solving }\end{array}$ & $\begin{array}{c}\text { Self- } \\
\text { Awareness } \\
\text { \& Self- } \\
\text { Control }\end{array}$ & \begin{tabular}{|c|} 
Innovative \\
Thinking
\end{tabular} \\
\hline $\begin{array}{l}\text { Officers Years } \\
\text { of Experience }\end{array}$ & & 1.000 & 0.081 & 0.096 & 0.033 & 0.125 & -0.043 & $-0.152^{*}$ & 0.108 & -0.103 \\
\hline People First & & & 1.000 & -0.079 & 0.046 & -0.099 & -0.009 & $-0.134^{*}$ & 0.027 & -0.049 \\
\hline Integrity & & & & & 1.000 & -0.024 & 0.048 & -0.084 & 0.043 & -0.027 \\
\hline $\begin{array}{l}\text { Decision } \\
\text { Making }\end{array}$ & & & & & & 1.000 & -0.038 & -0.054 & -0.051 & -0.083 \\
\hline $\begin{array}{c}\text { Planning, } \\
\text { Coordination \& } \\
\text { Implementation }\end{array}$ & & & & & & & 1.000 & -0.014 & -0.087 & 0.062 \\
\hline $\begin{array}{c}\text { Innovative } \\
\text { Thinking }\end{array}$ & & & & & & & & & & 1.000 \\
\hline
\end{tabular}

Note: (a) ** indicates Correlation is significant at the 0.01 level; (b) * indicates Correlation is significant at the 0.05 level; and (c) The above is a Spearman's rho correlation (given unequal distance between competency levels). We avoided using Pearson correlation as it assumes equal distance between each of the competency levels. 
Table A6.2: 2-Step Cluster Analysis on SPSS for all the 218 Surveyed Officers

\section{Clusters}

Input (Predictor) Importance

$\square 1.0 \square 0.8 \square 0.6 \square 0.4 \square 0.2 \square 0.0$

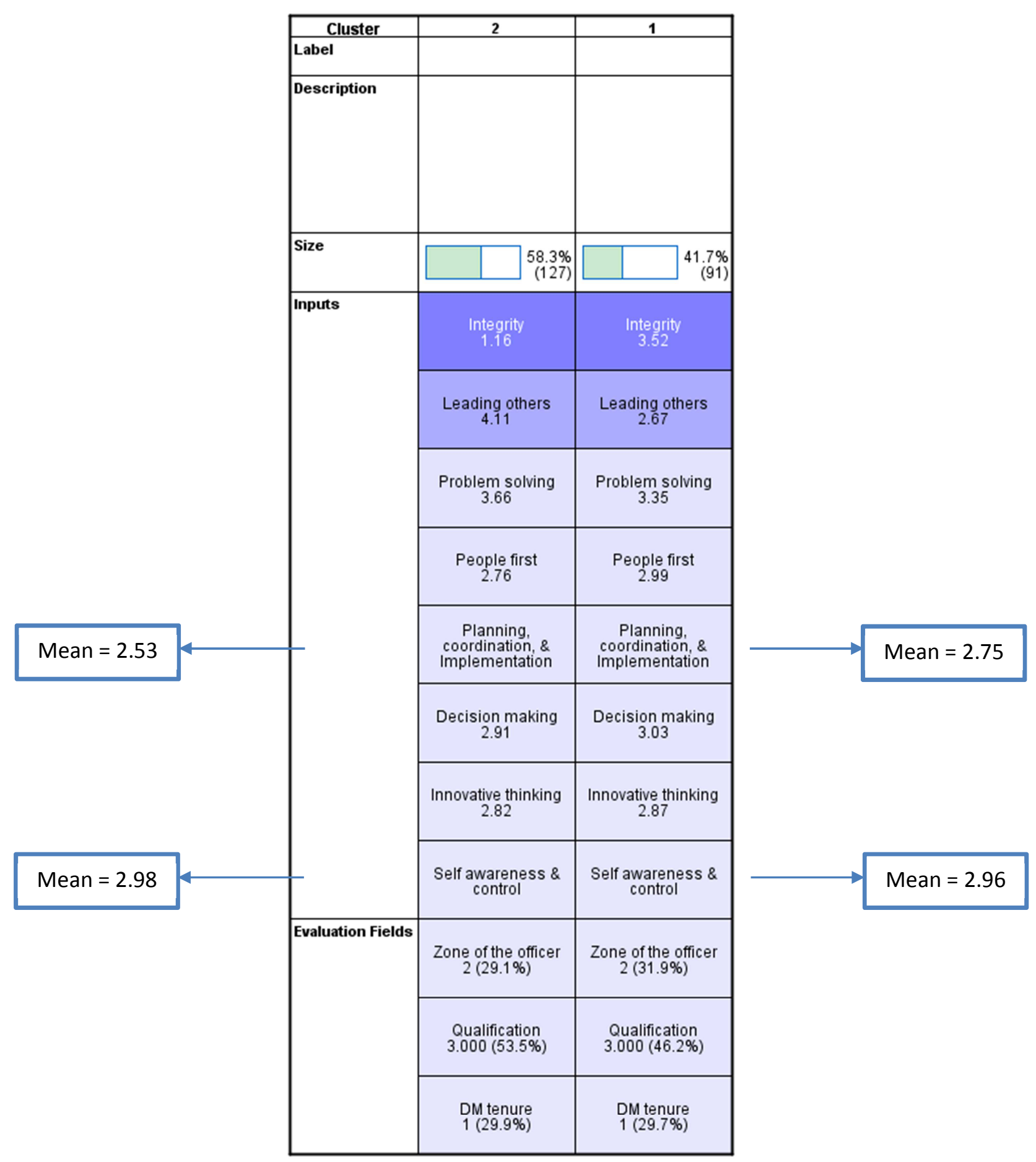


Note: Further data investigation revealed that (a) respondent officers with 'Commerce' and 'Professional Course' qualification had a stronger representation in Cluster 2 over Cluster 1. (b) Zone wise investigation revealed a very strong representation of Central Zone officers (i.e., Chhattisgarh and Madhya Pradesh) in Cluster 1. On the other hand, West and AGMUT Zone officers had a stronger representation in Cluster 2. (c) When tenure as DM was used to see the difference, we found that Cluster 2 had slightly more officers with nil and very low experience as DM. 